\title{
On the Cultivation of Intercultural Sensitivity in Chinese Students Preparing to Study Abroad
}

\author{
Liping Xia \\ Intensive Language Training Center/ \\ College of International Studies \\ Sichuan University \\ Chengdu, China \\ lipingxia@netease.com
}

\begin{abstract}
With the rapid development of education globalization, increased attention should be paid to the Intercultural Sensitivity and the Intercultural Communication Competence of students planning to study in a multicultural environment. The purpose of this study is to discuss intercultural sensitivity cultivation in Chinese students who are going to study in foreign universities. A review of empirical studies on the intercultural sensitivity level of Chinese students is conducted and the results show that the intercultural sensitivity level of Chinese students (including students preparing to study abroad) is generally medium. Suggestions are put forward as to developing the intercultural sensitivity of Chinese students who are going to study in a foreign university. This paper is one of the very few papers addressing intercultural sensitivity development of Chinese students planning to study in a multicultural environment.
\end{abstract}

Keywords-Intercultural Sensitivity(ICS); Intercultural Sensitivity Scale (ISS); students preparing to study abroad; suggestions

\section{INTRODUCTION}

Studying abroad is not only an important channel for students to benefit from high-quality educational resources which can cultivate a large number of talents for our country, but also a significant way for more and more young people to enrich their life experience and enhance their competitive ability. The number of Chinese students who choose to receive their higher education in a foreign university has been greatly increasing in the recent years. According to statistics released by the Ministry of Education of China, the annual number of Chinese students studying abroad rose from 134,000 in 2006 to 544,500 in 2016, an increase of more than 4 times in a span of ten years. More attention should be paid to the Intercultural Sensitivity (ICS) and the Intercultural Communication Competence (ICC) of students planning to study in a multicultural environment, so as to find measures to better prepare them in the aspect of cross-cultural adaptation. This study aims to discuss the cultivation of intercultural sensitivity in students who are going to study abroad.

\section{INTERCULTURAL SENSITIVITY}

Intercultural sensitivity refers to a person's potential to adroitly discriminate and experience cultural differences in an intercultural setting. It has been considered as an essential factor for carrying out effective intercultural communication. Milton Bennett (1986) proposed Developmental Model of Intercultural Sensitivity (DMIS ). According to him, intercultural sensitivity is an individual's organizational or constructive orientations towards cultural differences in intercultural settings. The DMSI constitutes a progression of three ethnocentric orientations (Denial, Defense, and Minimization) and three ethnorelative orientations (Acceptance, Adaptation, and Integration).

Based on their previous research on intercultural sensitivity, Chen \& Starosta (1997) contended that intercultural sensitivity is the emotional dimension of a person's intercultural competence, including having interest in other cultures, having adequate sensitivity to notice cultural differences and the willingness to modify his or her behavior to adapt to other cultures. Intercultural sensitivity is a dynamic concept construing a person's desire to understand, appreciate and accept differences among cultures. As an independent concept, intercultural sensitivity constitutes six elements: selfesteem, self-monitoring, open-mindedness, empathy, interaction involvement, and non-judgment. Chen and Starosta (2000) further explained that people who are inter-culturally sensitive can easily get to the level of "dual identity", enjoy, accept and adapt to cultural differences. The more sensitive a person is towards differences among cultures, the easier he or she could adapt to a new environment.

\section{INSTRUMENTS OF MEASURING INTERCULTURAL SENSITIVITY}

Several inventories were designed by scholars as instruments to measure an individual's intercultural sensitivity, two of which have been widely applied and frequently cited by researchers in the study of intercultural sensitivity and intercultural competence. One is Intercultural Sensitivity Inventory (ICSI) designed by Bhawuk and Brislin (1992), and the other is Intercultural Sensitivity Scale (ISS) developed by Chen and Starosta (2000). 
Based on their research on subjects in America and Japan, Bhawuk and Brislin (1992) developed Intercultural Sensitivity Inventory (ICSI) to measure an individual's intercultural sensitivity from the perspective of individualism and collectivism. ICSI is a seven level Likert Scale of 46 items involving three dimensions of emotion, cognition and behavior, aiming to understand the different ways an individual can behave in a new culture, the open-mindedness concerning the differences he or she encounters, and the behavioral flexibility he or she demonstrates.

Chen and Starosta (2000) designed the Intercultural Sensitivity Scale (ISS) based on previous theories and research. There are 24 items in this instrument which contains five factors of intercultural sensitivity, and the five factors are: (1) Interaction Engagement, (2) Respect for Cultural Differences, (3)Interaction Confidence, (4) Interaction Enjoyment and (5) Interaction Attentiveness. Chen and Starosta predicted and finally confirmed that people with a higher score in ISS test are with a higher level of ICS.

\section{EMPIRICAL STUDIES ON INTERCULTURAL SENSITIVITY IN CHINA}

With the development of the research of intercultural communication in China, a number of empirical researches have been conducted in this field over the past years. Peng Peng Shiyong (2006) conducted a study on 833 subjects consisted of English major college students, non-English major college students and transnational corporation employees respectively based in Mainland China and Thailand. By using the Intercultural Sensitivity Scale (ISS) developed by Chen \& Starosta, he made a comparison of the subjects' intercultural sensitivity. The results show that in both Mainland China and Thailand English major students and transnational employees had a significantly higher level of intercultural sensitivity than non-English major students. It is implied that foreign language learning experience as well as intercultural communication experience has positive influence on the building of intercultural sensitivity. Zhou Xingying (2007) did a survey to assess the intercultural sensitivity level of 91 English major juniors from the international business school of a Chinese university by utilizing Chen and Starosta's ISS. The results indicate that the students' level of ICS generally remains medium. Sun Nailing \& Liu Zhezhe (2012) adopted the ISS of Chen \& Starosta to measure non-English major postgraduates' intercultural sensitivity in mainland China. The results show that the intercultural sensitivity level of the subjects is low. Yang Kaiyu (2013) conducted an investigation on the intercultural sensitivity level of English majors in a college in Guangxi Province, and it is revealed that the intercultural sensitivity level of the students is medium and that the correlation coefficient between the subjects' intercultural sensitivity and English grades is not high.

In the recent years, more surveys have been conducted to test the intercultural sensitivity level of college students of different majors. The results turn out to be similar, that is, the intercultural level of the subjects is generally medium, although the mean of the five factors varies from one survey to another. Liu Jin (2014) took 317 non-English major students as subjects and tested their intercultural sensitivity level by utilizing Chen \& Starosta's ISS. The results show that the subjects' intercultural sensitivity level is a bit higher than the intermediate. And among the five factors, the subjects' Respect of Cultural Differences is the highest, followed by Interaction Engagement, Interaction Attentiveness, Interaction Enjoyment and Interaction Confidence. Li Yan (2015) conducted a survey on the intercultural sensitivity level of college students in Beijing by using Chen \& Starosta's ISS and the findings show that the overall situation of 757 students' intercultural sensitivity is at a medium level, and the intercultural sensitivity level of liberal arts students is obviously higher than that of science and engineering science students. Zhang Shuyuan, et al. (2015) adopted Chen \& Starosta' ISS to measure the intercultural sensitivity level of 605 medical undergraduate students. They found that the subjects' intercultural sensitivity is at medium level, and the mean of Respect for Cultural Differences is highest while the mean of Interaction confidence remains the lowest, with Interaction Engagement, Interaction Enjoyment and Interaction Attentiveness in the middle. Huang Yueying (2016) did a survey on the intercultural sensitivity level of 85 nonEnglish major postgraduates at Southwest Minzu University. The results show that the subjects' intercultural sensitivity level is intermediate, and the correlation coefficient analysis reveals that the five constructs of ISS are correlated.

Little research has been done on the intercultural sensitivity level of Chinese students preparing to study overseas. Xia Liping and Han Zengjun(2015) adopted Chen \& Starosta's ISS to measure the overall level of intercultural sensitivity of 114 Chinese students preparing for studying abroad and the correlation between the five factors of intercultural sensitivity which are Interaction Engagement, Respect for Cultural Differences, Interaction Confidence, Interaction Enjoyment and Interaction Attentiveness. The results show that most subjects' level of ICS remains medium, and among the five factors of intercultural sensitivity, the subjects' Interaction Attentiveness is the highest, followed by Interaction Engagement, Interaction Confidence, Respect for Cultural Differences and Interaction Enjoyment. Moreover, there is a very close relationship between the subjects' Respect for Cultural Differences and Interaction Enjoyment and as well as that between Interaction Engagement and Interaction Attentiveness. One factor of each two affects the other mutually.

\section{SUGgestions FOR CUlTIVATING INTERCULTURAL SENSITIVITY IN STUdENTS PREPARING TO STUdy ABROAD}

Studying abroad is an important approach to making the most of foreign educational resources and training highquality talents for our country. It is also a way for an increasing number of young people to gain more life experiences and to raise personal competitiveness. In the recent years more and more foundation programs have been opened to prepare students who plan to study abroad. As students have to take language tests and meet the GPA requirements, they would tend to ignore the intercultural communication part in the preparatory process which may lead to the result that the students are not able to interact appropriately and effectively with people of other cultures 
when they are abroad. Effective intercultural interaction includes the ability to communicate in the target language, developed intercultural sensitivity, and knowledge of cultural aspects of the target language. Good levels of intercultural sensitivity help individuals to initiate intercultural communication, to enjoy intercultural interaction and to gain a satisfactory intercultural communication effect. Therefore, it is of great importance for students to develop intercultural sensitivity when they are preparing to study in a cross-cultural setting. Suggestions are given as follows with regards to cultivating intercultural sensitivity in students who prepare to study in a foreign country.

1) On the side of education institutions which provide foundation programs preparing students to study abroad, it's very necessary to put intercultural communication on the curriculum. Such courses as the introduction of the target language culture and cross-cultural communication should be provided to the students. Meanwhile, intercultural activities or events should be organized to enrich students' cross-cultural communication experiences in both aspects of cognition and practice.

2)As for teachers, on one hand, they must realize the significance of intercultural sensitivity to themselves and to their students, and constantly develop their own intercultural sensitivity and improve their intercultural communication abilities. On the other hand, teachers should strengthen culture teaching alongside language teaching, and enable the students to acquire as much knowledge about the culture of the target language as possible and teach them to show respect for different cultures. In the meantime, in the classroom teachers could adopt such methods as video watching, role plays, and group discussions, etc. to cultivate the students' intercultural sensitivity and enhance their intercultural interaction. It is also advisable to hold cross-culture knowledge contests or crossculture theme speeches among the students so as to create the atmosphere of cross-culture learning and sharing.

3)As to students, it is especially important for them to raise intercultural awareness, develop a positive attitude towards cross-cultural communication, improve confidence in crosscultural communication and actively participate in intercultural activities. Listening to foreign songs, reading foreign novels, watching foreign TV programs and films, travelling overseas, making friends with people across different cultures and social groups, etc. could not only help students gain knowledge about foreign cultures but also enable students to develop intercultural sensitivity cognitively and behaviorally. It is also very important for students to have adequate knowledge about the culture of their mother tongue-the Chinese culture, as intercultural communication is also a process of understanding and sharing meanings of different cultures. Having adequate knowledge of the Chinese culture can not only build their intercultural confidence but also encourage their intercultural engagement, and hence increase their intercultural enjoyment.

\section{CONCLUSION}

With the number of Chinese students who choose to receive their higher education in a foreign university constantly increasing in the recent years, more attention should be paid o the Intercultural Sensitivity and the Intercultural Communication Competence of students planning to study in a multicultural environment. Previous empirical studies show that the intercultural sensitivity level of Chinese students is generally medium, a bit low in some cases. Several suggestions are given in this study as to developing intercultural sensitivity in students who are going to study abroad. In the context of globalisation, these suggestions are also applicable to education institutions and personnel aiming to cultivate globally competent individuals.

\section{ACKNOWLEDGMENT}

This paper is supported by Sichuan University Intensive Foreign Language Training · Education Internationalisation Special Project.

\section{REFERENCES}

[1] X. H. Wang, "What will we expect when the number of students studying abroad reaches a million?", China Scholars Abroad, 2007(4), p.8. (In Chinese)

[2] http://www.moe.gov.cn/jyb_xwfb/xw_fbh/moe_2069/xwfbh_2017n/xwf b_170301/170301_sjtj/201703/t20170301_297676.html. (In Chinese)

[3] M. J. Bennett, "A developmental approach to training for intercultural sensitivity", International Journal of Intercultural Relations, 1986,10(2), pp.179-196..

[4] M. J. Bennett, Basic Concepts of Intercultural Communication, Yarmouth : Intercultural Press, 1998, pp.32.

[5] D., Bhawuk, \& R. Brislin, "The measurement of intercultural sensitivity using the concepts of individualism and collectivism", International Journal of Intercultural Relations, 1992, 16(4), pp.413-436.

[6] G. M. Chen, Review of the Concept of Intercultural Sensitivity. Biennial Convention of the Pacific and Asian Communication Association. Honolulu. 1997

[7] G M, Chen, W. J. Starosta, "The development and validation of the intercultural sensitivity scale”, .Human Communication, 2000.

[8] S. Y. Peng, "Influence of Nationality and Profession on Intercultural Sensitivity", Journal of Zhejiang University,2006,(1), pp.74-80. (In Chinese)

[9] X. Y. Zhou, "An Analysis of the Intercultural Sensitivity of College Students", Shandong Foreign Language Teaching Journal,2007,(5), pp.62-66. (In Chinese)

[10] N. L. Sun, Z.Z. Liu, “An Investigation and Study on Non-English Major Postgraduates' Intercultural Sensitivity”, Journal of Baoji University of Arts and Sciences(Social Science Edition),2012,(8), pp.89-93. (In Chinese)

[11] K. Y. Yang, "The testing of the intercultural sensitivity of English majors", Foreign Language Education and Teaching, 2013(9),pp.122123,131. (In Chinese)

[12] J. Liu, "An investigation on the intercultural sensitivity level of nonEnglish major students ", Journal of Jining University, 2014(6), pp.105108. (In Chinese)

[13] Y. Li, "Research on the Intercultural Sensitivity of College Students in Beijing “, Theory and Practice of Education, 2015 (18), pp.13-15. (In Chinese)

[14] S. Y. Zhang, J. Zhao, Z. D. Liu, "A survey on the intercultural sensitivity level of medical undergraduate students", Management Observer, 2015(1), pp.144-146. (In Chinese) 
[15] Y. Y. Huang, "An analysis on the intercultural sensitivity of non-English major postgraduates", Journal of Educational Institute of Jilin Province, 2016 (7), pp. 75-78. (In Chinese)
[16] L. P. Xia,, Z. J. Han, "An Investigation on the Intercultural Sensitivity of Chinese Students on Study-abroad Programs", Modernization of Education, 2015 (7), pp.20-23. (In Chinese) 